\title{
Site-specific Management for the Twenty-first Century
}

Pierre C. Robert

ADDITIONAL INDEX WORDS. precision agriculture, precision farming, GPS, GIS, sustainable, crop quality, food safety

Summary. A better awareness of soil and crop condition variability within fields brought the notion, in the early 1980 s that variable management within fields by zones rather than whole fields would increase profitability by doing the right thing at the right place in the right way. At the same time, the microcomputer became available and made possible the acquisition, processing, and use of spatial field data as well as the development of a new kind of farm machinery with computerized controllers and sensors. Precision agriculture (PA) has been considered for most common cropping systems and some specialty crops, worldwide. It is particularly well adapted to high value crops such as many horticultural crops. PA is still in infancy and its adoption varies greatly but precision agriculture is the agricultural system of the future. It offers a variety of potential benefits in profitability, productivity, sustainability, crop quality, food safety, environmental protection, on-farm quality of life, and rural economic development.

$\mathrm{T}$

.L. Friedman (1999) wrote in his best seller book about global ization The Lexusand the Olive Tree, "it is not a histori-

cal accident that E ast Germany, the Soviet U nion, ....General $M$ otor, and IBM all either collapsed or were forced to radically restructure at roughly the same time.... They all got hit with a disease I called: microchip immune deficiency syndrome or MIDS.... it is the disease of the globalization era. It can strike any company or country, large or small, .... MIDS: A disease than can afflict any bloated, overweight, sclerotic system in the post-cold war era. It is contracted by companies or countries that fail to inoculate themselves against changes brought about by the microchip, and the democratization of technology, finance, and information-which created a much faster, more open and more complex market place, with a whole new set of efficiencies."

If globalization has impacted countries, industries, and a variety of businesses, it has started to impact agriculture, or more generally natural resources management, as well. Site-specific management (SSM ), also called precision agriculture (PA), is one of the best tools to answer this major challenge facing agriculture. 
Friedman (1999) gives the following example: "Gary Wagner... and histwo brothers own a 4,200-acre farm in the heart of M innesota Red River Valley... As the 1900s rolled around, Gary could see what was happening to the farm business: either you got big and wereable to take advantage of economies of scale and played in the global farmers market, or you got swallowed up... they began to look for an edge... in 1993 a firm approached with a wacky new technology. It was a microchip-based sensor that could be attached to his wheat combine... Wagner suddenly found out exactly how much wheat was being harvested from every acre of his field. What I found out was something of a surprise, said Wagner. I t was a common belief that yield did not vary very much from one area of your field to another... Instead of having to work with information from a centralized pool that was based on averages for the region for the average farmer, wewere able to tailor everything to ourselves... E veryone has the same tractors, the same combines, the same basic land, the same water, so the only thing that can distinguish you from your competitor now is who hasmoreknowledge Armed with more knowledge, Wagner can now delegate more things to his workers so he can concentrate on the key strategy... Wagner is still a pioneer in what is known as precision farming."

This excerpt shows the importance of site-specific management or precision agriculture as a key agricultural management system of the 21st century.

\section{Site-specific management}

From themid-1970sinto theearly 1980 s, a better awareness of soil and crop condition variability within fields grew from better field investigation methods including soil survey, soil sampling, aerial photography, and crop scouting. An important outcome was to perceivepotential benefits of management within fields by zones rather than whole fields for increased profitability. At the same time, the microcomputer became available and made possible the acquisition, processing, and utilization of spatial field data as well as the development of a new kind of farm machinery with computerized controllers and sensors. This was the beginning of a new agricultural management concept called initially farming by soil types then site-specific management. Today, it iscommonly named Precision farming or precision agriculture. Q uickly, it generated a strong interest mainly because of associated new technologies, the concept made good sense, and it offered new routes for agri-industries and agri-businesses. To- day, it can be said that the PA concept has been considered for most common cropping systems and somespecialty crops, world wide. I t has been defined in many ways but basically it is information technology. PA is not just the injection of new technologies but it is rather an information revolution, made possible by new technologies that result in a higher level, a more precise farm management system. A more complete definition is "the application of a holistic management strategy that uses information technology to bring data from multiple sources to bear on decisions associated with agricultural production, marketing, finance, and personnel" (Olson, 1998).

The concept of SSM was initiated for application of fertilizers to midwestern corn (Zea maysL.) and soybeans [ Glycinemax (L.) $M$ err.], it has been adapted to a variety of practices, crops, and countries. From variable rate applications of fertilizers, it now encompasses all management practices on a spatial and temporal basis: sampling, tillage, planting (rate and variety), fertilizing (rate, blend, and type including manure), crop protection product applications (rate, mix), harvesting, and irrigation. From corn, soybean, and small grains, it now applies to a variety of plants such as rice (Oryza L.), cotton (Gossypium L.), peanut (A rachis hypogaea L.), sugarbeet (Beta vulgarisL.), sugarcane(Saccharum L.), and potato (Solanum tuberosum L.); vegetables; orchards and vineyards; and more recently tropical cropssuch as palm oil (Elaeis guineensisL.) and banana (M usa paradisiaca L.). Furthermore it is entering new domains such as precision turf management, precision pasture and range management, and precision tree management. From the midwestern states, it has entered most U.S. states and Canadian provinces; South and Central America, particularly Argentina, B razil, C hile, Costa Rica, and M exico; most countries of western Europe and it is considered in some eastern European countries; Australia and $\mathrm{N}$ ew Zealand; and Asia, for example, J apan and M alaysia. Some research and development projects are starting in $\mathrm{C}$ hina. $\mathrm{H}$ orticultural crops are prime candidates for SSM since most of them are high value crops and quality is a major concern capable of bringing a significant added value to the commodities.

In addition to increased profitability, as a result of better management practices and the development of farm information systems, SSM can bring additional benefits such as increased crop quality, lower management risk, food safety documentation, environmental protection, and rural development through new skills transferable to other activities. 
T able 1. G rowers use of precision agriculture services in 1998: precision leader dealership versus random dealership sample. (Akridge and Whipker, 1998.

\begin{tabular}{lcr}
\hline \multirow{2}{*}{$\begin{array}{l}\text { G rower } \\
\text { use of }\end{array}$} & \multicolumn{2}{c}{ Dealers } \\
\cline { 2 - 3 } & Precision (\%) & R andom (\%) \\
\hline Soil sampling with G PS & 40 & 8 \\
Field mapping & 55 & 29 \\
Field mapping with GI Sw & 31 & 6 \\
Yield monitor & 26 & 14 \\
E nhanced seed & 70 & 52 \\
VRT & & \\
$\quad$ M anual & 20 & 18 \\
$\quad$ Controller (single) & 20 & 7 \\
$\quad$ Controller (multi) & 19 & 4 \\
zPrecision dealers are either already offering precision agriculture services or have definite plans to do so shortly. \\
yRandom dealers are less service-oriented, offering fewer traditional services and less custom application. \\
xG lobal positioning system. \\
wG eographic information system. \\
'Variable rate technology: site specific application of inputs.
\end{tabular}

\section{Status of site-specific management adoption}

Presently, site-specific management or precision agriculture is still much in infancy. I t is a holistic agricultural system but, today, only some elements of the whole system are available. Adoption of PA practicesisstill at an early stage. A survey sent to agricultural retailers in the U nited States is based on two samples of dealers. The first survey includes dealers committed to precision technology (leaders) and are either al ready offering PA services or have definite plans to do so shortly. D ealers in the second survey (random) were less service-oriented, offering fewer traditional services and less custom application (Akridge and Whipker, 1998). The survey indicates that adoption by growers of PA practices is still limited. Growers use of PA servicesfrom the leader sample are soil sampling with global positioning system (GPS) (40\%), field mapping with geographic information system (GIS) $(31 \%)$, and yield monitoring (26\%) (Table 1).

H owever, the survey shows that a largegroup of dealersare progressively offering PA services. The most common PA practices offered by leader dealerships are (T able 2) soil sampling with GPS (82\%), site-specific agronomicinterpretations (77\%), field mapping with GIS (74\%), yield map analysis $(61 \%)$, and variable rate applications of fertilizers with a simple controller (59\%).

Principal barriers for adoption of PA by growers are cost $(49 \%)$, attitude-slow adopter (41\%), new skills
(21\%), and cropping system (11\%) (Table 3).

Another survey was executed in four north-central states (I llinois, Indiana, lowa, and Wisconsin) to determine the level and factors influencing the adoption decision of PA practices (Khanna et al., 1998). Table 4 indicates that nonadopters have a lower education level, no computer, less experience, a part-time occupation, and a smaller farm. $O$ ther conclusions on causes for nonadoption are
- uncertainty on returns

- investments on new equipment and information acquisition systems

- lack of demonstrated impacts on yields.

\section{Research needs}

Recent surveys are showing that the infrastructure of PA services is developing and the adoption by producers of some practices continues to increase. Much research and development are in progress in universities, government agencies, and industries (Robert et al., 1998). But needs are important in engineering technology, management, understanding of natural condition variability, profitability, environmental protection, and technology transfer (Robert, 1999). The most frequent research topic needs were ranked as follow:

1. D evelopment of real-time sensors for soil and plant characterization.

2. Remote sensing techniques for soil and crop condition detection, and management.

3. Q uantification of PA impacts on the environment.

4. D evelopment of protocols for sampling procedures.

5. E conomics of PA practices.

6. Quantification of spatial and tem-

Table 2. Precision agriculture services offered in 1998: precision leader dealership versus random dealership sample (Akridge and Whipker, 1998).

\begin{tabular}{lcc}
\hline & \multicolumn{2}{c}{ Dealers } \\
\cline { 2 - 3 } Services & & Random (\%) $^{\mathbf{y}}$ \\
\hline Custom application of & 65 & 40 \\
$\quad$ Fertilizer & 55 & 40 \\
$\quad$ Pesticide & & \\
O ther soil sampling & 80 & 26 \\
$\quad$ Grid & 28 & 35 \\
Soil survey & 4 & 20 \\
$\quad$ one & & \\
Precision & 82 & 28 \\
Soil sampling with GPS & 88 & 34 \\
Field mapping & 74 & 24 \\
Field mapping with GI Sw & 38 & 8 \\
Yield monitor: sale & 61 & 12 \\
Yield map analysis & 77 & 22 \\
$\quad$ Agronomic interpretation & & \\
VRT & & 23 \\
M anual & 42 & 17 \\
Controller (single) & 59 & 7 \\
Controller (multi) & 31 &
\end{tabular}

zPrecision dealers are either already offering precision agriculture services or have definite plans to do so shortly. yR andom dealers are less service-oriented, offering fewer traditional services and less custom application.

${ }^{x}$ lobal positioning system.

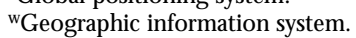

Wariable rate technology: site specific application of inputs. 
Table 3. Barriers for adoption of precision agriculture by growers included in either a precision leader dealership or a random dealership sample (Akridge and Whipker, 1998).

\begin{tabular}{lcc}
\hline Barriers & \multicolumn{2}{c}{ Dealer samples } \\
\cline { 2 - 3 } to growers & Precision (\%)z & Random (\%)y \\
\hline Cost & 49 & 42 \\
Slow adopter & 41 & 38 \\
Cropping program & 11 & 31 \\
M anagement expertise & 21 & 13 \\
Other & 4 & 11 \\
\hline
\end{tabular}

2Precision leaders are either already offering precision agriculture services or have definite plans to do so shortly. 'R andom dealers are less service-oriented, offering fewer traditional services and less custom application.

Table 4. C haracteristics of adopters of an advanced application technology (K hanna et al., 1998).

\begin{tabular}{lcc}
\hline & \multicolumn{2}{c}{ F armers } \\
\cline { 2 - 3 } Characteristics & $\begin{array}{c}\text { Adopters } \\
\mathbf{N = \mathbf { 1 4 4 }}\end{array}$ & $\begin{array}{c}\text { N onadopters } \\
\mathbf{N = 6 1 0}\end{array}$ \\
\hline Less than 50 years of age (\%) & 48 & 42 \\
Less than high school education (\%) & 38 & 54 \\
Less than 25 years of experience (\%) & 42 & 36 \\
Full time (\%) & 93 & 88 \\
O wnership of a computer (\%) & 68 & 41 \\
A verage farm size (ha-ac) & $496-1226$ & $308-760$ \\
\hline
\end{tabular}

poral natural resources variability. 7. M ethods for data analysis and interpretation.

8. U nderstanding relationships between yield, natural conditions, and input variables.

9. D evelo pment of practical crop models for PA management.

10. Development of improved spatial data analysis methods.

11. D evelopment of yield sensors.

12. M ethodologies for developing soil and crop site-specific prescriptions.

13. D evelopment of educational programs.

\section{Conclusions}

Agricultural history shows that any significant technological enhancement of agricultural management to ok much development, education, and timebeforebeing used by a majority of producers. It took, for example, more than 30 years to see tractors fully utilized. A similar course should be ex- pected for precision agriculture, a holistic system requiring substantial new tools and skills. This is illustrated by recent remarks of precision agriculture producers and dealers: "we have tools but we still haven't learned what to do with the data", "the more data we have, the better off we are", "progress will be made in stages", and "thisisnot asilver bullet" (D ealer Progress, 1998).

Recent surveys are showing that the infrastructure of precision agriculture services is developing and the adoption by producers of some practices is increasing. K. O Ison (1998), wrote: "with the increasing complexity of farming, theincreasing risk farmers are exposed to, and the increasing pressure to lower production costs, the management is for improved information technology, greater information processing, and better decision aids". This requires very substantial efforts in research and development, particularly in the development of optimum site-specific management practices and in educational programs at all levels: technical, college undergraduate and graduate, and professional. Other needs include a broad spectrum of issuesin engineering technology, management, understanding of natural condition variability, profitability, environmental protection, and technology transfer.

Site-specific management or precision agriculture-information technology -is the agricultural system of the 21st century because it offers a variety of potential benefits in profitability, productivity, sustainability, crop quality, food safety, environmental protection, on-farm quality of life, and rural economic development.

\section{Literature cited}

Akridge, J.T. and L.D. Whipker. 1998. 1998 Precision agricultural services and enhanced seed dealership survey results. Purdue U niv. Ctr. Agr. Bus. Staff Paper 98-11.

Dealer Progress. 1998. So, now what? Dealer Progress 29(8):14-20.

Friedman, T.L. 1999. The lexus and the olive tree. FSG, $\mathrm{N}$ ew York.

Khanna, M., O.F. Epouhe, and R. H ornbacker. 1998. Adoption of site-specific crop management: Current status and likely trends. W orking Paper Ser. 15. Progr. Environ. and Resource Econ., Environ. Council, U niv. III., U rbana-Champaign.

O Ison, K. 1998. Precision agriculture: current economic and environmental issues, p. 213-220. In: T. T empestaand M. Thiene (eds.). Sixth J oint Conf. Food, Agr., and the Environ. 31 Aug.-2 Sept. 1998. U niv. $M$ inn., St. Paul.

Robert, P.C. 1999. Precision agriculture: Status and research needs. In: J. Stafford (ed.). Proc. 2nd E uropean Conf. Precision Agr. Soc. Chem. Ind., London.

Robert, P.C., R.H . Rust, and W.E. L arson (eds.). 1998. Proceedings of the fourth international conference on precision agriculture. 19-22 July, St. Paul, M inn. ASACSSA-SSSA, M adison, Wis. 